\title{
THE CONTEXT OF FIELDWORK PRACTICES IN COMPUTER AND NETWORKING ENGINEERING MAJOR AT VOCATIONAL SCHOOL
}

\author{
Erika Agustariansyah \\ Universitas Negeri Jakarta, Jakarta, Indonesia \\ Email: erikaagustariansyah@gmail.com \\ Yuliatri Sastrawijaya \\ Universitas Negeri Jakarta, Jakarta, Indonesia \\ Email: yuliatri_s@yahoo.com \\ Lipur Sugiyanta \\ Universitas Negeri Jakarta, Jakarta, Indonesia \\ Email: lipursugiyanti23@gmail.com
}

DOI: 10.35445/alishlah.v12i1.201

Accepted: June $8^{\text {th }}, 2020$. Approved: June $28^{\text {th }}, 2020$.

Published: June $30^{\text {th }}, 2020$

\begin{abstract}
Field Work Practice is a mandatory program that must be implemented for the delivery of vocational level education or Vocational High Schools. The purpose of this study was to get a more in-depth quality of the context of Fieldwork Practices in the Computer and Network Engineering major at SMK Negeri 3 OKU. This is intended to make understanding of the context clearer. The research method used descriptive qualitative research. The data collection method used interviews, observations, documentation, and questionnaires. The data analysis technique used three stages, namely data reduction, data presentation, discussion, and drawing conclusions. The findings concluded that the context aspect for legality is in accordance with the standard rules for implementing Fieldwork Practices from the government as set forth in the rules and procedures for issuing Fieldwork Practices. Whereas aspects of the characteristics of schools implementing Fieldwork Practices are adjusted to operational standards set by schools and industry. In the context aspects of the needs of the industrial has also been built in accordance with an agreement from the industry. The results of this study also recommend that SMK Negeri 3 OKU continue to increase the amount of collaboration with industry and increase the competence of students and supervisors.
\end{abstract}


Al-Ishlah: Jurnal Pendidikan - ISSN: 2087-949o (p); 2597-940X (e)

Vol. 12, No. 1 (2020)

Keywords: Fieldwork Practice, Vocational School, Technology Major

\title{
PRAKTEK KERJA LAPANGAN PADA JURUSAN TEKNIK KOMPUTER DAN JARINGAN DI SEKOLAH MENENGAH KEJURUAN
}

\begin{abstract}
Abstrak
Praktik Kerja Lapangan merupakan program wajib yang harus dilaksanakan bagi penyelenggaran pendidikan tingkat kejuruan atau Sekolah Menengah Kejuruan. Tujuan penelitian ini adalah untuk mendapatkan lebih mendalam kualitas aspek konteks penyelenggaraan Praktik Kerja Lapangan pada jurusan keahlian Teknologi Komputer dan Jaringan di SMK Negeri 3 OKU. Hal ini dimaksudkan agar pemahaman terhadap aspek konteks menjadi lebih jelas. Metode penelitian yang digunakan adalah penelitian kualitatif deskriptif. Adapun metode pengumpulan data menggunakan wawancara, pengamatan, dokumentasi, dan angket. Teknik analisis data menggunakan tiga tahap yaitu reduksi data, penyajian data, diskusi, dan penarikan kesimpulan. Hasil temuan menyimpulkan bahwa aspek konteks untuk legalitas telah sesuai dengan standar aturan pelaksanaan Praktik Kerja Lapangan dari pemerintah yang tertuang pada aturan dan tata terbit Praktik Kerja Lapangan. Sedangkan aspek karakteristik sekolah penyelenggaraan Praktik Kerja Lapangan disesuaikan dengan standar operasional yang telah ditetapkan oleh sekolah dan pihak industri. Pada aspek konteks tentang kebutuhan dunia industri juga telah terbangun sesuai dengan kesepakatan dari pihak industri. Hasil penelitian ini juga merekomendasikan agar SMK Negeri 3 OKU terus meningkatkan jumlah kerjasama dengan pihak industri dan melakukan peningkatan kompetensi siswa dan guru pembimbing.
\end{abstract}

Kata Kunci: PKL, SMK, Program Teknologi

\section{PENDAHULUAN}

Jenjang pendidikan pada tingkat Sekolah Menengah Kejuruan (SMK) memberikan nilai lulusan berbeda. Hal ini disebabkan karena lulusan dari SMK telah memiliki kompetensi yang dibutuhkan oleh dunia industri ataupun dunia usaha. Artinya bahwa sekolah kejuruan memberikan kebutuhan manusia untuk mempertahankan hidup. Seperti yang dikatakan oleh Finch \& Crunkilton menyatakan bahwa tujuan pendidikan dibagi menjadi dua kategori, yakni : education for life and education for earning a living (Bukit, 2014). Jadi, proses pembelajaran dan pengajaran di SMK juga memberikan bekal untuk menghadapi kebutuhan persaingan dunia kerja dengan berbagai macam kompetensi. Peraturan 
Al-Ishlah: Jurnal Pendidikan - ISSN: 2087-9490 (p); 2597-940X (e)

Vol. 12, No. 1 (2020)

Pemerintah No.29 Tahun 1990 Pasal 1 Tentang Pendidikan Menengah, "Pendidikan Menengah Kejuruan adalah pendidikan pada jenjang menengah yang mengutamakan pengembangan kemampuan peserta didik untuk jenis pekerjaan tertentu" (1990). Peraturan tersebut menyiratkan bahwa Sekolah Menengah Kejuruan (SMK) didirikan untuk memfokuskan jenis program keahlian yang diminati dan untuk mengantisipasi kebutuhan tenaga kerja menengah yang berkualitas dan siap pakai di dunia usaha dan dunia industri.

Dari peraturan tersebut, Kementerian Pendidikan Nasional telah menerapkan Pendidikan Sistem Ganda (PGS) yang mampu memenuhi kebutuhan penyelenggaraan pendidikan di SMK sesuai dengan peraturan yang telah berlaku. PSG merupakan sistem pendidikan kejuruan yang melaksanakan pembelajaran di sekolah, dan di industri. Artinya bahwa proses pembelajaran dilaksanakan di sekolah dan proses pelatihan diselengarakan di industri sebagai komponen untuk mengetahui keberhasilan program pendidikan di SMK yang saling memiliki keterkaitan (Bukit, 2014). Dari pemahaman tersebut dapat disimpulkan bahwa proses penyelenggaraan pendidikan di SMK tidak hanya berorientasi pada pembelajaran di kelas saja, tetapi juga pembelajaran secara langsung melalui praktik di lapangan. Dalam dunia pendidikan SMK dikenal dengan sebutan kegiatan Praktik Kerja Industri (Prakerin) atau disebut juga Praktik Kerja Lapangan (PKL).

SMK Negeri 3 OKU menyediakan 8 Kompetensi keahlian, salah satunya adalah program keahlian atau jurusan Teknik Komputer dan Jaringan (TKJ). PKL pada program keahlian TKJ di SMK Negeri 3 OKU wajib dilaksanakan pada semester kedua kelas XI. Dengan demikian, keahlian siswa memiliki kesesuaian antara pengetahuan teori yang dipeoroleh siswa di kelas dengan kebutuhan dunia industri. Selain itu, tujuan dari kompetensi TJK dapat tercapai sesuai dengan visi dan misi sekolah. Adapun kompetensi dari program TKJ yang harus dimiliki oleh siswa adalah memiliki pengetahuan, keterampilan dan sikap propesional kerja agar kompeten dalam: 1) menginstal perangkat komputer baik itu personal maupun jaringan; 2) menginstal sistem operasi dan aplikasi; 3) menginstal jaringan lokal LAN (Local Area Network); 4) menginstal sistem operasi server; 5) administrasi server dalam jaringan; 6) perancangan WAN (Wide Area Network); 7) menjadi integrator komputer; 8) membangun jaringan VOIP (Voice Over Internet Protocol); dan 9) membangun Server Cloud Computing. Rumusan tujuan tersebut memberikan gambaran bahwa lulusan SMK pada Kompetensi Teknik Komputer dan Jaringan sangat diharapkan untuk mampu melakukan sebuah pekerjaan dibidang komputerisasi dan jaringan dengan sebaik-baiknya baik itu di dunia usaha maupun industri dan perkantoran.

Namun, dalam kenyataannya pelaksanaan PKL masih menghadapi kendala dan belum sesuai dengan harapan dan tujuan yang ingin dicapai dalam program 
Al-Ishlah: Jurnal Pendidikan - ISSN: 2087-9490 (p); 2597-940X (e)

Vol. 12, No. 1 (2020)

kompetensi tersebut. Pelaksanaan Program Praktik Kerja Lapangan disusun bersama antara sekolah dan dunia kerja untuk memenuhi kebutuhan peserta didik dan sebagai kontribusi dunia kerja terhadap pengembangan program pendidikan SMK. Praktik Kerja Lapangan di berlakukan bagi peserta didik yang belum menyelesaikan studi, sebagai bentuk integral antara pembelajaran teori di sekolah dan praktik di lapangan sesuai dengan kurikulum yang berlaku. Sehingga terjadi sinergi antara keilmuan yang diperoleh di kelas dengan kebutuhan praktik di dunia industri. Dengan kata lain bahwa kegiatan PKL dapat memberikan wawasan pengetahuan berbeda antara teori dan praktik langsung, meningkatkan kompetensi dan keterampilan yang dimiliki oleh siswa, dan melatih etos kerja yang tinggi.

Dengan demikian, keahlian siswa memiliki kesesuaian antara pengetahuan teori yang dipeoroleh siswa di kelas dengan kebutuhan dunia industri. Artinya bahwa konteks dari penyelenggaraan PKL telah sesuai dengan peraturan dan kebutuhan di lapangan. Pada aspek konteks dalam pelaksanaan PKL difokuskan pada legalitas, karakteristik dunia usaha dan kebutuhan dari dunia usaha ataupun sekolah dalam memenuhi kebutuhan kompetensi siswa. Namun, harapan pemenuhan dari konteks PKL belum seutuhnya terpenuhi.

Berdasarkan pada observasi awal ditemukan beberapa permasalahan dari pelaksanaan PKL di SMK Negeri 3 OKU yang selama ini belum diteliti dan diselesaikan secara ilmiah. Permasalahan pertama adalah hasil evaluasi PKL menunjukkan daya serap lulusan yang masih rendah. Hal ini disebabkan karena adanya ketidakrelevanan kompetensi dari lulusan program TKJ di SMK Negeri 3 OKU. Para lulusan masih memiliki kompetensi rendah dan lemah dalam penguasaan teknologi komputer yang dibutuhkan didunia industri. Permasalahan kedua adalah tempat pelaksanaan PKL yang belum sesuai dengan kebutuhan para siswa, dikarenakan banyak pihak industri yang menolak dijadikan tempat pelaksanaan Praktik Kerja Lapangan. Penolakan tersebut disebabkan karena tidak sesuai antara jurusan dengan kebutuhan pihak industri, adanya ketidakcocokkan antara bidang keahlian peserta didik dengan pekerjaan yang dilakukan di tempat praktik. Permasalahan ketiga adalah guru pembimbing sering kali tidak melakukan kunjungan ke tempat pelaksanaan PKL secara rutin dan teratur untuk menilai peserta PKL, sehingga menyebabkan kebutuhan akan konteks dari PKL belum terpenuhi. Pelaksanaan PKL terkesan merupakan kegiatan yang digunakan untuk menggugurkan kewajiban dan belum sesuai dengan aturan dalam konteks kebutuhan PKL.

Oleh karena itu, penelitian ini berfokus pada evaluasi konteks pelaksanaan program PKL di SMK Negeri 3 Oku untuk jurusan TKJ. Evaluasi yang dilakukan bisa menggunakan berbagai macam model evaluasi seperti CIPP, logoc model, dan sebagainya. Banyak penelitian sebelumnya yang telah dilakukan dalam menguji atau mengimplementasikan model CIPP dan Outcomes untuk 
Al-Ishlah: Jurnal Pendidikan - ISSN: 2087-9490 (p); 2597-940X (e)

Vol. 12, No. 1 (2020)

mengevaluasi suatu program. Gunung \& Darma (2019) telah menunjukkan efektifitas program pengajaran di Politeknik Negeri Bali dilihat dari keterkaitan konteks, input, proses dan produk. Model evaluasi CIPP merupakan model evaluasi yang lebih lengkap karena mencakup evaluasi formatif dan sumatif. Evaluasi konteks, input, proses, dan produk dapat dipraktikkan dalam rangka pengambilan keputusan (peran formatif) dan penyajian informasi mengenai akuntabilitas (Mahmudi, 2011). Pengembangan model layanan evaluasi berbasis context, input, process, product (CIPP) merupakan salah satu bentuk solusi dari permasalahan guru BK dalam melaksanakan evaluasi terkait dengan layanan informasi yang telah dilakukan. Pengembangan model CIPP ini muncul karena kurang pahamnya guru BK dalam melakukan evaluasi sehingga menyebabkan kesulitan untuk mengetahui keberhasilan pelaksanaan layanan informasi di sekolah, lemahnya akuntabilitas dan kesulitan untuk melakukan perbaikan serta pengembangan. Melalui model context input process product (CIPP) ini, evaluasi layanan informasi dapat dilakukan secara komprehensif (Muyana, 2017). CIPP sering digunakan pula untuk mengevluasi efektifitas program pembelajaran. Selama ini evaluasi pembelajaran menggunakan model CIPP cukup efektif seperti pembelajaran IPA (Bhakti, 2017), pembelajaran Bahasa Inggris (Ulumi, 2016), program pelatihan (Ulumi, 2016), program peningkatan pembelajaran (Zhang et al., 2001), evaluasi kurikulum SMK (Baysha \& Astuti, 2016), evaluasi program mengajar senam (Terry, 2005), dan evaluasi standar profesionalisme guru (Suryobroto, Hastuti, \& Jatmika, 2018). Frechtling (2015) yang memaparkan kelemahan dan kelebihan model logis. Sedangkan Medeiros, et al., (2005) telah menggunakan model logis untuk menguji program Pendidikan gizi masyarakat dan model ini telah digunakan untuk mengembangkan mekanisme pelatihan. Penelitian berbeda dari Holliday (2014) telah menggunakan model logis untuk mengevaluasi konsep tantangan yang diimplementasikan pada program sekolah, apakah program yang digunakan untuk mendukung kemampuan guru memberikan dampak terhadap sekolah.

Dari hasil penelitian-penelitian yang telah dilakukan sebelumnya diketahui bahwa kajian difokuskan dengan implementasi model evaluasi suatu program seperti CIPP. Namun, pada kajian ini lebih fokus pada evaluasi aspek konteks yang merupakan bagian utama yang harus dipertimbangkan oleh suatu sekolah dalam menyelenggarakan PKL. Walaupun demikian, aspek konteks tersebut menjadi bagian dari tahapan evaluasi suatu program. Hal ini yang memberikan nilai penelitian berbeda dengan penelitian sebelumnya. Penelitian ini berbeda karena mengkaji lebih dalam tentang aspek pelaksanaan PKL. Maka penelitian ini wajib dilakukan dengan alasan bahwa kebutuhan pemahaman terhadap konteks pelaksanaan PKL menjadi bagian yang mampu memberikan keutuhan suatu 
Al-Ishlah: Jurnal Pendidikan - ISSN: 2087-9490 (p); 2597-940X (e)

Vol. 12, No. 1 (2020)

program, pemahaman terhadap kebutuhan dunia usaha dan pencapaian tujuan visi misi sekolah, serta kebutuhan kompetensi siswa yang harus dipenuhi.

Berdasarkan pada paparan tersebut dapat diketahui bahwa tujuan dari penelitian ini adalah untuk mengetahui lebih mendalam konteks dari pelaksanaan kegiatan PKL pada jurusan TKJ di SMK Negeri 3 Oku. Penelitian ini diharapkan dapat bermanfaat untuk memberikan informasi tentang kebutuhan konteks dalam penyelenggaraan program PKL untuk program PKL di SMK Negeri $3 \mathrm{Oku}$, sehingga pihak sekolah dapat meningkatkan kekurangan penyelenggaraan PKL. Selain itu, pemahaman konteks dari PKL bisa memberikan pemahaman terhadap implementasi tujuan dari pelaksanaan PKL dari peraturan yang telah pemerintah rancang. Di samping hal tersebut, sekolah kejuruan dapat menghasilkan lulusan yang mampu bersaing dan kompeten di dunia usaha dan industry yang terus berkembang sejalan dengan persaingan dunia saat ini.

\section{METODE PENELITIAN}

Kegiatan penelitian dilakukan di SMK Negeri 3 Oku sebagai salah satu sekolah yang memberikan dampak positif terhadap kebutuhan lulusan yang berkompeten di bidang TKJ untuk daerah Oku yang beralamatkan di Kec. Baturaja Timur, Kabupaten Ogan Komering Ulu, Sumatera Selatan. Penelitian ini menggunakan metode deskriptif kualitatif. Penelitian kualitatif digunakan untuk memahami tentang fenomena sosial yang terjadi dalam perspektif manusia sesuai dengan kejadian yang ada di lapangan (Ary, Jacobs, Sorensen, \& Razavieh, 2010). Jadi, penelitian ini mengeksplorasi lebih mendalam dari lapangan tentang konteks untuk penyelenggaraan program PKL yang diselenggarakan di SMK Negeri 3 Oku. Penelitian ini menggambarkan kecenderungan fenomena simbolik dan mencerminkan apa yang terjadi di lapangan terhadap konteks dari penyelenggaraan PKL.

Prosedur penelitian terdiri dari tiga tahap, yaitu 1) pra-lapangan, 2) kegiatan lapangan dan 3) analisis intensif (J.Moleong, 2007). Proses pengumpulan data menggunakan observasi, wawancara, dan dokumentasi.

1. Wawancara dilakukan pada sumber informasi (informan). Informan adalah wakil kepala sekolah bagian kurikulum dan guru pembimbing PKL

2. Pengamatan yang dilakukan peneliti untuk mengunjungi lokasi penelitian guna mengetahui kondisi aktual terkait informasi / data yang dikumpulkan.

3. Dokumentasi yang digunakan untuk menganalisis dan mengumpulkan data dari dokumen-dokumen mengenai peraturan tentang penyelenggaraan PKL di SMK 
Al-Ishlah: Jurnal Pendidikan - ISSN: 2087-9490 (p); 2597-940X (e)

Vol. 12, No. 1 (2020)

4. Angket yang ditujukan kepada wakil kepala sekolah bagian kurikulum dan guru pembimbing PKL

Sumber data dalam penelitian ini adalah data primer dan data sekunder. Data primer dalam penelitian ini diambil dari dokumen dan wawancara yang telah dilakukan kepada informan secara langsung oleh peneliti. Sedangkan data sekunder diambil dari hasil observasi dan kajian pustaka yang berkaitan dengan kebutuhan terhadap konteks penyelenggaraan PKL di SMK Negeri 3 OKU. Adapun aspek konteks yang diteliti terdiri dari indikator-indikator seperti legalitas pelaksanaan PKL, karakteristik sekolah penyelenggara PKL, dan kebutuhan dunia usaha terhadap kompetensi lulusan yang dibutuhkan dunia usaha.

Teknik analisis data dalam penelitian ini dilakukan dengan teknik analisis data kualitatif yang dimulai dengan memeriksa semua data yang dikumpulkan dari berbagai sumber, yaitu wawancara, observasi, dan dokumen. Analisis data menggunakan tahapan reduksi data, penyajian data, diskusi, dan penarikan kesimpulan.

\section{HASIL DAN PEMBAHASAN}

Data yang telah diperoleh dianalisis dan dirangkum dalam tabel berikut ini.

Tabel 1 Legalitas Pelaksanaan Praktek Kerja Lapangan (PKL)

\begin{tabular}{llll}
\hline No & \multicolumn{1}{c}{ Nama Dokumen } & Ada & Tidak \\
& & \\
\hline 1. & Tata tertib dan aturan pelaksanaan PKL di SMKN 3 OKU & X & \\
2. & Surat keputusan/Surat Tugas Kepala Sekolah SMKN 3 & X & \\
& OKU tentang kepanitian PKL & & \\
\end{tabular}

Tabel 1 memaparkan dengan jelas bahwa konsep konteks dari legalitas pelaksanaan PKL di SMK Negeri 3 OKU telah dilaksanakan sesuai dengan panduan operasional yang telah dirancang. Sekolah telah membuat tata tertib dan aturan bagi siswa ataupun industri yang menerima siswa untuk magang. Dari hasil wawancara diketahui bahwa kepala sekolah bagian kurikulum telah meminta tim (panitia) pelaksana PKL untuk membuat tata tertib bagi siswa yang harus dipatuhi karena berkenaan dengan aspek penilaian pada komponen kepribadian. Selain itu, sekolah juga membuat kesepakatan aturan pelaksanaan PKL yang harus diperhatikan selama siswa magang. Aturan ini tentunya menjadi bagian penilaian 
Al-Ishlah: Jurnal Pendidikan - ISSN: 2087-9490 (p); 2597-940X (e)

Vol. 12, No. 1 (2020)

dari perspektif instruktur di industry dalam menilai perkembangan kemampuan siswa. Pihak sekolah juga telah membuat legalitas yang sesuai dengan peraturan melalui adanya surat keputusan ataupun surat tugas kepada gugus pelaksana PKL.

Tabel 2 Karakteristik Sekolah Penyelenggara Program PKL

\begin{tabular}{llll}
\hline No & Nama Dokumen & Ya & Tidak
\end{tabular}

1. Apakah jurusan keahlian Teknik Komputer dan Jaringan telah $\mathrm{X}$ terakreditasi dengan nilai baik?

2. Apakah kegiatan PKL yang dilaksanakan di SMKN 3 Oku untuk $X$ Kompetensi Keahlian Teknik Komputer dan Jaringan sudah lebih dari 10 kali?

3. Apakah guru pembimbing PKL memiliki kualifikasi akademik $\mathrm{X}$ minimum sarjana (S1) atau diploma empat (D-IV)?

4. Apakah guru telah mengajar sesuai dengan latar belakang $\mathrm{X}$ pendidikan yang dimilikinya untuk keahlian TKJ?

5 Apakah guru pembimbing PKL memiliki kesehatan jasmani dan $\mathrm{X}$ rohani yang bagus dalam menjalankan tugasnya?

6. Apakah guru memiliki integritas kepribadian dan bertindak sesuai dengan norma agama, hukum, sosial, serta peraturan dan ketentuan $\quad \mathrm{X}$ yang berlaku?

7. Apakah guru memiliki kemampuan komunikasi yang efektif dan santun dengan sesama guru, tenaga kependidikan, siswa, dan $\mathrm{X}$ orangtua siswa?

8. Apakah guru selalu mengembangkan kemampuannya dalam mengajar?

$\mathrm{X}$

9. Apakah guru mata pelajaran produktif memiliki sertifikat keahlian sesuai dengan mata pelajaran yang diampu agar mendukung $\mathrm{X}$ kegiatan PKL?

10. Apakah guru memiliki kemampuan mengembangkan penilaian untuk mengukur kemampuan siswa?

11. Apakah guru menggunakan teknik penilaian sesuai dengan karakteristik mata pelajaran?

$\mathrm{X}$

12. Apakah guru menilai sikap dan kepribadian siswa sebagai informasi untuk menentukan nilai akhir semester?

X $\quad \mathrm{X}$

13. Apakah sekolah menjalin kerjasama dengan DU/DI dalam melaksanakan magang guru?

14. Apakah sekolah menjalin kerjasama dengan DU/DI dalam melaksanakan Praktik Kerja Lapangan (PKL)? 
Al-Ishlah: Jurnal Pendidikan - ISSN: 2087-949o (p); 2597-940X (e)

Vol. 12, No. 1 (2020)

15. Apakah kompetensi keahlian Teknik Komputer dan Jaringan sudah bekerja sama dengan salah satu ATPM (Agen Tunggal Pemegang Merk) dan menjadi sekolah binaannya?

16. Apakah jadwal pelaksanaan Praktik Kerja Lapangan (PKL) secara rutin sudah teragendakan dalam kurikulum setiap tahunnya?

17. Apakah ada kebijakan yang dikeluarkan oleh pihak sekolah dalam mensukseskan pelaksanaan Praktik Kerja Lapangan (PKL)?

18. Apakah ada sarana prasarana yang dipersiapkan oleh pihak sekolah dalam melaksanakan Praktik Kerja Lapangan (PKL) setiap

19. tahunnya?

Apakah dengan pelaksanaan Praktik Kerja Lapangan (PKL) dapat $\quad X$ meningkatkan mutu guru pembimbing dengan adanya transfer ilmu

20. dari dunia industri?

Apakah peserta didik pada tahun ajaran 2018/2019 khususnya pada

$\mathrm{X}$ kompetensi keahlian TKJPraktik Kerja Lapangan (PKL) mengikuti kegiatan PKL

Tabel 2 menunjukkan hasil analisis aspek konteks untuk karakteristik sekolah yang melaksanakan kegiatan PKL. Data tersebut telah diolah dengan hasil pengamatan dan wawancara yang menyimpulkan bahwa keahlian program TKJ telah terakreditasi dengan predikat A. Artinya bahwa pengelolaan program TKJ sangat baik dan sistematis. Apalagi kegiatan PKL juga telah diadakan semenjak sekolah didirikan. Sedangkan pada aspek sumber tenaga pengajar atau guru telah memiliki latar belakang yang sesuai dengan keahlian pada program TKJ. Sekolah juga telah menentukan aspek kesehatan, kepribadian, dan kemampuan komunikasi yang harus dimiliki. Sekolah selalu melakukan kegiatan pengembangan guru dalam mengajar seperti seminar ataupun workshop sesuai dengan perkembangan kebutuhan dunia industry. Partisipasi sekolah terhadap program pemerintah melalui seleksi sertifikasi guru juga dilakukan secara teratur dan terjadwal. Para guru juga diharuskan memiliki sertifikat keahlian yang dikeluarkan oleh pemerintah secara nasional ataupun internasional, sehingga guru mampu membimbing dengan baik siswa-siswa yang melaksanakan PKL. Namun, kekurangan sekoleh terlihat pada jalinan kerjasama antara sekolah dengan dunia industry untuk melaksanakan pelatihan atau magang guru. Kegiatan kerjasama hanya sebatas untuk menyalurkan siswa yang PKL. Bagi para siswa mudah untuk mencari tempat PKL dan juga siswa harus memenuhi standar syarat untuk kegiatan PKL. Dari hasil analisis tersebut disarankan bahwa sekolah seharusnya mengembangkan kerjasama dengan pihak DU/DI untuk peningkatan keahlian guru dan beberapa Agen Tunggal Pemegang Merek untuk menampung lulusan yang terbaik. 
Al-Ishlah: Jurnal Pendidikan - ISSN: 2087-949o (p); 2597-940X (e)

Vol. 12, No. 1 (2020)

Adapun hasil analisis data pada aspek kebutuhan DU/DI untuk mensukseskan pelaksanaan PKL adalah.

Tabel 3 Kebutuhan DU/DI Untuk Penyelenggara Program PKL

No

Nama Dokumen

Ya Tidak

1. Apakah keahlian TKJ melaksanakan program Praktik Kerja di Dunia $\mathrm{X}$ Usaha / Lapangan (PKL) sesuai dengan ketentuan yang berlaku?

2. Apakah jenis industry yang berkembangan di bidang TKJ yang $X$ bekerjasama dengan sekolah?

3. Apakah ada kesulitan sekolah dalam meningkatkan jumlah MoU $\mathrm{X}$ dalam pelaksanaan PKL?

4. Apakah panitia PKL memilki data penempatan siswa PKL di X industri?

5 Apakah panitia PKL melakukan seleksi untuk penempatan para $\mathrm{X}$ siswa di industri?

6. Apakah panitia melakukan persiapan peserta PKL mulai dari administrasi sampai pemberangkatan?

7. Apakah sekolah melakukan seleksi guru pembimbing yang sesuai $X$ dengan kriteria dari dunia industry yang menjadi tempat PKL para siswa?

8. Apakah guru pembimbing melakukan pengawasan siswa PKL X bersamaan dengan instruktur di industry sesuai dengan kesepakatan kriteria penilaian yang telah dirancang oleh sekolah?

9. Apakah sistem penilaian dilakukan secara dua arah oleh pihak $\mathrm{X}$ sekolah dan industry?

Apakah guru pembimbing melakukan kunjungan secara terjadwal ke $\quad \mathrm{X}$

10. tempat PKL sesuai dengan waktu yang ditetapkan oleh pihak industri?

Apakah panitia PKL melakukan sidang pelaporan hasil PKL? $\quad \mathrm{X}$

11. Apakah pihak DUDI memberikan saran yang membangun untuk $\mathrm{X}$

12. sekolah dalam penyelenggaraan PKL?

Apakah pihak panitia PKL memberikan sertifikat PKL yang sesuai $\quad X$

13. dengan hasil dari penilaian DUDI?

14. Apakah proses pengawasan terhadap siswa yang PKL dilakukan $X$ secara ketat oleh pihak DUDI sesuai dengan standar SOP dari

15 industry dan kriteria sekolah?

Apakah nilai yang diberikan oleh pihak industry ditentukan oleh sekolah? 
Al-Ishlah: Jurnal Pendidikan - ISSN: 2087-9490 (p); 2597-940X (e)

Vol. 12, No. 1 (2020)

Tabel 3 disimpulkan bahwa aspek konteks untuk kebutuhan DUDI dalam penyelenggaraan PKL telah memenuhi standar dari keberadaan DUDI. Namun, pada bagian sarana dan prasarana yang dibutuhkan oleh siswa memang tidak disediakan keseluruhan oleh sekolah. Pihak sekolah tidak mau membebani siswa dengn kebutuhan yang berkaitan dengan diri siswa itu sendiri. Selama ini, SMK Negeri 3 OKU telah menyiapkan kebutuhan sarana PKL yang berkaitan dengan kegiatan PKL itu sendiri sehingga siswa bisa fokus pada kebutuhan pribadi masing-masing. Sekolah juga memiliki kebijakan yang sangat baik dalam memberikan penilaian terhadap siswa PKL. Walaupun sekolah telah menentukan kriteria penilaian bagi peserta didik yang PKL, pihak industri tetap memiliki kebebasan untuk mengikuti kriteria tersebut atapun memberikan penilaian sesuai dengan standar yang dimiliki oleh industri. Dengan demikian, hal ini memberikan pemahaman bahwa penilaian dilakukan sesuai dengan standar dalam bekerja yang professional. Pada komponen ini, sekolah bertujuan untuk meningkatkan kualitas penyelenggaraan PKL dan kompetensi siswa yang sesuai dengan kebutuhan lapangan. Namun, siswa mengalami kesulitan dalam menentukan peningkatan jumlah industry yang bekerjasama. Hal ini disebabkan karena industry teknologi memiliki kriteria yang sangat tinggi dalam menerima peserta PKL ataupun lulusan. Pada komponen inilah sekolah masih selalu berusaha meningkatkan standar industry yang bergerak dibidang teknologi. Dari hasil wawancara, sekolah sering melakukan pelatihan untuk peningkatan kompetensi siswa dan guru, siswa memberikan tes kompetensi bagi siswa yang akan melaksanakan PKL sebagai salah satu syarat, dan sekolah memberikan beasiswa bagi siswa dan guru berprestasi untuk melakukan studi banding ke sekolah ataupun industry.

Dari hasil temuan diketahui bahwa SMK Negeri 3 OKU telah melaksanakan pembelajaran di sekolah, dan di industri, dimana pembelajaran di sekolah dan pelatihan di industri merupakan dua komponen yang berasal dari program yang tidak dapat terpisahkan, yaitu : Pendidikan Sistem Ganda (PSG). Dipertegas juga dalam struktur kurikulum Sekolah Menengah Kejuruan (SMK) yang menyebutkan bahwa "Beban belajar SMK meliputi kegiatan pembelajaran tatap muka (TM), praktik sekolah (PS), dan kegiatan kerja praktik di dunia usaha/industri (PI)." Pada program Pendidikan Sistem Ganda (PSG), sekolah dengan pihak industri secara bersama-sama terlibat dan bertanggung jawab mulai dari tahap perencanaan program, tahap implementasi sampai tahap penentuan kelulusan peserta didik serta upaya pemasaran tamatannya (Suwarman \& Pardjono, 2014).

Peserta didik SMK menjalani magang di industri beberapa bulan (paling cepat 3 bulan) selama mereka menjalani sistem pendidikan tiga tahun atau empat tahun di SMK. Praktik Kerja Lapangan merupakan lahan pelatihan profesionalisme peserta didik di mana peserta didik harus melatih proses 
Al-Ishlah: Jurnal Pendidikan - ISSN: 2087-9490 (p); 2597-940X (e)

Vol. 12, No. 1 (2020)

penguasaan keterampilan, kreatifitas dan inisiatif agar dapat melatih peserta didik mengembangkan ide-idenya, tanggung jawab terhadap pekerjaan, serta senantiasa memperhatikan prestasi dalam bekerja sehingga dapat meningkatkan minat untuk berwirausaha pada dirinya sendiri, dan mampu menghadapi persaingan di dunia industri. Jadi, kegiatan PKL bagi siswa di SMK Negeri 3 OKU menjadi sarana yang sangat bermanfaat bagi siswa dalam mengimplementasikan keahliannnya yang telah dipelajari di kelas. Karena lulusan yang harus siap bekerja dan memiliki keterampilan yang dibutuhkan dunia usaha.

Selain itu, pelaksanaan praktek kerja industri cukup bermanfaat dalam mempersiapkan siswa memasuki dunia kerja (Syahroni, 2014). Perencanaan, pelaksanaan dan evaluasi serta pelaksanan praktik kerja industri harus sesuai dengan pedoman praktik kerja industri yang telah dirancang di sekolah (Saputra, Permana, \& Sriyono, 2017). Evaluasi program praktek kerja industri di SMK BPS \& K II Bekasi menggunakan model CIPP sudah cukup baik (Supadi, 2017). Penelitian lain yang telah dilakukan adalah penyiapan tenaga kerja yang kompeten harus disiapkan melalui kegiatan magang para siswa selama di sekolah (Emir, 2013). Pelatihan Kejuruan dan Pendidikan bertujuan untuk menyediakan pasar kerja dengan keterampilan di tingkat sub-profesional dan tidak ada lagi pendidikan kelas dua (Rahman, Hanafi, Mukhtar, \& Ahmad, 2014), sama seperti yang terjadi di Romania (Popescu \& Roman, 2018). Selain itu evaluasi program praktek kerja juga dapat dilakukan sesuai dengan basis kekuatan sekolah (Maras, Splett, Reinke, Stormont, \& Herman, 2014).

Pelaksanaan program PKL pada program keahlian Teknik Komputer dan Jaringan di SMK Negeri 3 OKU telah mencapai pada evaluasi konteks yang harus disesuaikan dengan kebutuhan persaingan global. Hal ini disebabkan karena ilmu pengetahuan dari teknologi komputer selalu berkembang dengan sangat cepat. Dengan demikian, para lulusan di SMK pada program keahlian Teknik Komputer dan Jaringan harus selalu mengikuti perkembangan teknologi. Jika hal ini tidak dilakukan, maka para lulusan tidak dapat diserap di dunia industri ataupun dunia usaha. Oleh karena itu, sekolah sebagai institusi yang memiliki kewajiban untuk memberikan dan meningkatkan kompetensi para siswa, harus selalu melakukan perubahan baik dari segi ilmu pengetahuan teori maupun praktik di lapangan. Hal ini telah diketahui dari aspek konteks yang disiapkan dengan baik oleh sekolah. Dari kondisi tersebut, maka penelitian ini telah memberikan gambaran yang jelas untuk kesiapan konteks penyelenggaraan PKL di SMK Negeri 3 OKU. Hasil temuan pada aspek konteks memberikan pemahaman berbeda dengan penelitian sebelumnya yang dikaji secara keseluruhan. Namun, penelitian ini mengkaji lebih dalam aspek konteks pada setiap komponen. Dengan demikian, hasil kajian menjadi lebih berkembang. 
Al-Ishlah: Jurnal Pendidikan - ISSN: 2087-949o (p); 2597-940X (e)

Vol. 12, No. 1 (2020)

\section{SIMPULAN}

Hasil temuan aspek konteks untuk penyelenggaraan PKL di SMK Negeri 3 OKU telah memiliki nilai standar yang sesuai aturan dari pihak sekolah ataupun pemerintah. Pihak sekolah merancang kegiatan PKL yang berpedoman pada peraturan pemerintah yang telah dituangkan pada aturan dan tata tertib PKL. Legalitas ini dirancang agar pelaksanaan PKL dapat mencapai tujuan pendidikan. Sedangkan aspek konteks untuk karakteristik penyelenggara PKL juga telah dipenuhi dengan baik dan konteks kebutuhan DUDI yang sesuai bidang keilmuan TKJ juga telah dipenuhi dan disiapkan dengan sangat baik oleh sekolah. Melalui Praktik Kerja Lapangan diharapkan dapat menciptakan tenaga kerja yang professional. Dimana para peserta didik yang melaksanakan pendidikan tersebut diharapkan dapat menerapkan ilmu yang didapat, dan sekaligus mempelajari dunia industri. Tanpa diadakannya Praktik Kerja Lapangan ini peserta didik tidak dapat langsung terjun ke dunia industri karena peserta didik belum mengetahui situasi, dan kondisi lingkungan kerja.

Dari analisis konteks ini berimplikasi pada penyelenggaraan PKL yang fokus pada peningkatakan kerjasama pihak sekolah dengan industry-industri yang bergerak di bidang keahlian Teknologi Komputer dan Jaringan. Jadi hasil penelitian merekomendasikan kepada sekolah bahwa agar pelaksanaan PKL untuk komponen legalitas, karakteristik sekolah dan kebutuhan DUDI harus selalu berpedoman pada aturan yang berlaku saat ini. Selain itu, pihak sekolah juga bisa menuangkan dalam aturan dengan mengeluarkan kebijakan penyelenggaraan PKL yang sesuai dengan perkembangan keilmuan teknologi ataupun kebutuhan persaingan global saat ini. Apalagi bidang teknologi beberapa tahun mendatang akan menjadi kebutuhan yang sangat besar baik di dunia usaha ataupun pendidikan.

\section{DAFTAR PUSTAKA}

Ary, D., Jacobs, L. C., Sorensen, C., \& Razavieh, A. (2010). Introduction to Research in Education (8 Edition). CA: Cengage Learning.

Baysha, M. H., \& Astuti, E. R. P. (2016). EVALUASI CIPP (CONTEXT INPUT PROCESS PRODUCT) PENERAPAN KURIKULUM SMK. Jurnal Teknologi Pendidikan: Jurnal Penelitian Dan Pengembangan Pembelajaran, 1(1), 23-39. Retrieved from http://ojs.ikipmataram.ac.id/index.php/jtp/article/view/599.

Bhakti, Y. B. (2017). EVALUASI PROGRAM MODEL CIPP PADA PROSES 
Al-Ishlah: Jurnal Pendidikan - ISSN: 2087-949o (p); 2597-940X (e)

Vol. 12, No. 1 (2020)

PEMBELAJARAN IPA. JIPFRI: Jurnal Inovasi Pendidikan Fisika Dan Riset Ilmiah, 1(2).

Bukit, M. (2014). Strategi dan Inovasi Pendidikan Kejuruan Dari Kompetensi ke Kompetensi. Bandung: Alfabeta.

Frechtling, J. A. (2015). Logic Models. International Encyclopedia of the Social \& Behavioral Sciences, 299-305. https://doi.org/10.1016/B978-0-08097086-8.10549-5

Gunung, I. N., \& Darma, I. K. (2019). Implementing the Context, Input, Process, Product (CIPP) Evaluation Model to Measure the Effectiveness of the Implementation of Teaching at Politeknik Negeri Bali (PNB). International Journal of Environmental and Science Education - IJESE, 14(1). Retrieved from http://www.ijese.net/makale/2101

Holliday, L. R. (2014). Using logic model mapping to evaluate program fidelity. Studies in Educational Evaluation, 42, 109-117. https://doi.org/10.1016/J.STUEDUC.2014.04.001

J.Moleong, L. (2007). Metodologi Penelitian Kualitatif. Bandung: PT. Remaja Rosdakarya.

Mahmudi, I. (2011). CIPP: Suatu Model Evaluasi Program Pendidikan. Jurnal AtTa'dib, 6(1).

Medeiros, L. C., Butkus, S. N., Chipman, H., Cox, R. H., Jones, L., \& Little, D. (2005). A Logic Model Framework for Community Nutrition Education. Journal of Nutrition Education and Behavior, 37(4), 197-202. https://doi.org/10.1016/S1499-4046(06)60246-7.

Muyana, S. (2017). CONTEXT INPUT PROCESS PRODUCT (CIPP): MODEL EVALUASI LAYANAN INFORMASI. In Prosiding Seminar Bimbingan dan Konseling. Malang: UM. Retrieved from http://pasca.um.ac.id/conferences/index.php/snbk.

Peraturan Pemerintah Republik Indonesia, Nomor 29 Tahun 1990, Tentang Pendidikan Menengah (1990). Jakarta.

Suryobroto, A. S., Hastuti, T. A., \& Jatmika, H. M. (2018). Using the Context, Input, Process, and Product Evaluation Model (CIPP) to Evaluate Elementary School Teacher-Learner Program of Physical Education in Yogyakarta City. Advances in Social Science, Education and Humanities Research, 278. 
Al-Ishlah: Jurnal Pendidikan - ISSN: 2087-949o (p); 2597-940X (e)

Vol. 12, No. 1 (2020)

Suwarman, S., \& Pardjono, P. (2014). Pengelolaan praktik kerja industri pada program keahlian teknik pemesinan SMK se-Kabupaten Kulon Progo. Jurnal Pendidikan Vokasi, 4(1). https://doi.org/10.21831/jpv.v4i1.2537.

Terry, J. . (2005). Evaluasi Proses Belajar Mengajar Senam melalui Masukan dan Proses Model Context, Input, Process and Product (CIPP) di SLTP Kota Manado 2001. Jurnal Pendidikan Dan Kebudayaan, 11(52), 20. https://doi.org/10.24832/jpnk.v11i52.677.

Ulumi, Ö. G. (2016). EVALUATION OF ENGLISH AS A FOREIGN LANGUAGE PROGRAM - USING CIPP (CONTEXT, INPUT, PROCESS AND PRODUCT) MODEL. European Journal of English Language Teaching, 1(2). Retrieved from https://oapub.org/edu/index.php/ejel/article/view/377.

Zhang, G., Zeller, N., Griffith, R., Metcalf, D., Williams, J., Shea, C., \& Misulis, K. (2001). Using the Context, Input, Process, and Product Evaluation Model (CIPP) as a Comprehensive Framework to Guide the Planning, Implementation, and Assessment of Service-learning Programs. Journal of Higher Education Outreach and Engagement, 15(4), 57-84. Retrieved from http://openjournals.libs.uga.edu/index.php/jheoe/article/view/628 